\title{
FORMAÇÃO DE MUDAS DE Coffea arabica L. cv. RUBI UTILIZANDO SEMENTES OU FRUTOS EM DIFERENTES ESTÁDIOS DE DESENVOLVIMENTO
}

\author{
Coffea arabica L. cv Rubi seedlings formation from seeds or berries at \\ different developmental stages
}

\author{
Sttella Dellyzete Veiga Franco da Rosa', Leonardo Q. de Melo², André Delly Veiga ${ }^{3}$, \\ Sirlei de Oliveira ${ }^{4}$, Carlos Alberto Spaggiari Souza ${ }^{5}$, Vinícius de Araújo Aguiar ${ }^{6}$
}

\begin{abstract}
RESUMO
Sementes de cafeeiro apresentam germinação lenta e com baixo potencial de armazenagem, o que dificulta a formação de mudas em tempo hábil e em condições climáticas favoráveis à implantação da lavoura. A propagação do cafeeiro por meio de mudas oriundas de sementes é ainda largamente realizada e é altamente desejável a redução do tempo para a obtenção de mudas bem desenvolvidas e vigorosas, visando o bom estabelecimento do estande e a redução da porcentagem de replantio. Considerando que sementes de cafeeiro adquirem a sua máxima germinação nos estádios verde-cana e cereja, o presente trabalho foi realizado com o objetivo de testar alternativas para a obtenção de mudas, utilizando-se frutos ou sementes em vários estádios de desenvolvimento. O experimento foi conduzido no viveiro de mudas do Setor de Cafeicultura da Universidade Federal de Lavras. O delineamento foi de blocos casualizados, com quatro repetições e as mudas foram produzidas em sacolinhas, com substrato de terra, esterco, superfosfato simples e cloreto de potássio (substrato padrão). Foram testados nove tratamentos de semeadura empregando-se sementes ou frutos de Coffea arabica L. cv. Rubi: 1) frutos no estádio verde; 2) frutos no estádio verde, dez dias após a colheita; 3) frutos no estádio verde-cana; 4) frutos no estádio verde-cana, dez dias após a colheita; 5) frutos no estádio cereja; 6) sementes de frutos cereja secadas até $15 \%$ de teor de água; 7) sementes de frutos cereja secadas até $15 \%$ e sem pergaminho; 8) sementes de frutos cereja secadas até $15 \%$ de teor de água e préembebidas em água por seis dias; e 9) sementes de frutos cereja secadas até $15 \%$, sem pergaminho e pré-embebidas em água por seis dias. Cento e quarenta dias após o início do experimento foram avaliados a porcentagem de emergência (E), o índice de velocidade de emergência (IVE) e a porcentagem de plântulas com pelo menos um par de folhas verdadeiras (FV). Cento e oitenta dias, após o início do experimento, procedeu-se à avaliação das mudas, por meio de medições do diâmetro do caule (D), altura da planta (H), massa seca do sistema radicular (MSSR), massa seca da parte aérea (MSPA), área foliar (AF) e número de pares de folhas (NVF). Os tratamentos de semeadura de sementes sem pergaminho se destacaram em todas as características avaliadas e apresentaram praticamente o mesmo desempenho das mudas de sementes sem pergaminho e pré-embebidas em água por seis dias. Nas características de avaliação das mudas, os tratamentos de semeadura de frutos no estádio verde-cana e de sementes sem pergaminho não diferiram estatisticamente entre si e foram superiores à semeadura de sementes com pergaminho. A embebição de sementes de cafeeiro com pergaminho em água não oferece vantagens na formação de mudas.
\end{abstract}

Termos para indexação: Coffea arabica L., mudas, semeadura, frutos, sementes.

\section{ABSTRACT}

Coffee seeds present slow germination and poor storage potential, which makes it difficult seedling formation in a suitable time and under climatic conditions favorable to the crop establishment. The propagation of the coffee plant by means of seedlings coming from seeds is still widely accomplished and reduction of the time for the obtaining a good developed and vigorous seedlings is highly desirable, aiming at a good establishment of the stand and the reduction of the percentage of replanting. Considering that coffee seeds achieve their maximum germination at the green yellowish and red ripe stages, the present work was undertaken with the purpose of testing an alternative to obtain seedlings, by using both berries and seeds at several developmental stages. The experiment was conducted in the seedling nursery of the Coffee Culture Sector at the Federal University of Lavras. The design was in randomized blocks with four replicates and the seedlings were produced in bags with substrate of earth, manure, simple superphosphate and potassium chlorite (standard substrate). Nine sowing treatments were tested by utilizing seeds or berries Coffea arabica L. cv. Rubi: 1) berries at the green stage; 2) berries at the green stage 10 days after harvest; 3 ) berries at the green yellowish stage; 4) berries at the green yellowish stage 10 days after harvest; 5) berries at the red ripe stage; 6) seeds from red ripe berries dried to $15 \%$ of the water content; 7) seeds from red ripe berries dried to $15 \%$ and without parchment; 8 ) seeds from red ripe berries, dried to $15 \%$ of water parchment and with a parchment and pre-soaked in water for six days; and 9) seed from red ripe berry, dried to $15 \%$ without a parchment and pre-soaked in water for six days. One hundred and forty days after the start of the experiment, the percentage of emergence (E), emergency velocity index (EVI) and the percentage of seedlings with at least one pair of true leaves (TL) were evaluated. One hundred and eighty after the start of the experiment, the evaluation of the seedlings was proceeded by means of the measurements of stem diameter (D), seedling height $(\mathrm{H})$, root system dry matter (RSDM), shoot dry matter (SDM), leaf area (LA)

\footnotetext{
${ }^{1}$ Pesquisadora, Dra. Embrapa Café, CEPECAFÉ, Departamento de Agricultura/DAG da Universidade Federal de Lavras/UFLA - Cx. P. 3037 _ 37200-000 - Lavras, MG - sttelaveiga@ufla.br

²Engenheiro Agrônomo, Departamento Técnico da Agrichem do Brasil - lqmelo@yahoo.com.br

${ }^{3}$ Engenheiro Agrônomo, doutorando em Fitotecnia - Universidade Federal de Lavras/UFLA - Cx. P. 3037 - $37200-000$ - Lavras, MG - Bolsista CNPq - adelly2@yahoo.com.br

${ }^{4}$ Engenheiro Agrônomo, doutoranda em Fitotecnia - Universidade Federal de Lavras/UFLA - Cx. P. 3037 - $37200-000$ - Lavras, MG - Bolsista CNPq.

${ }^{5}$ Pesquisador Dr. CEPLAC/CEPEC/Linhares/ES - carlosspaggiari@bol.com.br

${ }^{6}$ Aluno do Curso de Agronomia - Universidade Federal de Lavras/UFLA - Cx. P. 3037 - 37200-000 - Lavras, MG - viniagro@yahoo.com.br
} 
and of the number of pairs of leaves (NPL). The treatments of sowing of seeds without a parchment stood out in every evaluated seed characteristics and presented practically the same performance of the seedlings of seeds without a parchment and pre-soaked in water for six days. In the characteristics of seedling evaluation, the treatments of berries of green yellowish and of seeds without a parchment did not differ statistically from one another and were superior to the sowing of seeds with a parchment. The soaking of coffee seeds with a parchment in water brings no advantage to seedling formation.

Index terms: Coffea arabica L.; seedlings, sowing, berries, seeds.

\section{(Recebido em 22 de setembro de 2004 e aprovado em 9 de maio de 2006)}

\section{INTRODUÇÃO}

O setor cafeeiro tem grande importância econômicosocial no Brasil, principalmente na Região Sudeste, responsável por mais de $50 \%$ da produção nacional (ANUÁRIO..., 2002/2003). Em face do aumento da competitividade do mercado internacional, torna-se necessária a busca de inovações tecnológicas para o setor cafeeiro, visando o aumento da eficiência da produção e a redução dos custos de produção.

Com o auxílio de técnicas que envolvem as áreas da biotecnologia e da cultura de tecidos, avanços têm sido obtidos na área de propagação do cafeeiro, mas a forma ainda mais utilizada é propagação por meio de mudas formadas a partir de sementes (CARVALHO, 1997; GUIMARÃES \& MENDES, 1998). As sementes de cafeeiro apresentam germinação lenta e baixo potencial de armazenagem, o que dificulta a formação de mudas em tempo hábil e em condições climáticas favoráveis à implantação da lavoura (GUIMARÃES, 2000). É altamente desejável a redução do tempo para a obtenção de mudas bem desenvolvidas e vigorosas, visando o bom estabelecimento do estande e a redução da porcentagem de replantio.

De acordo com Guimarães \& Mendes (1998), em condições de campo, a emergência ocorre entre 50 e 60 dias após a semeadura, sendo que, sob temperaturas abaixo de $25^{\circ} \mathrm{C}$ pode levar de 90 a 120 dias. Este fato é de extrema importância na maioria das regiões produtoras de Coffea arábica L., uma vez que as sementes de cafeeiro colhidas em maio/junho, estarão disponíveis ao viveirista no início da estação fria.

Desta forma, diversas pesquisas têm sido desenvolvidas, para se entender as causas da lenta e desuniforme germinação de sementes de cafeeiro, ou ainda para melhorar a qualidade das sementes ou o seu potencial de armazenamento, sempre com o objetivo final de obtenção de mudas sadias e vigorosas e em época cujo clima seja mais adequado à implantação da lavoura.

Embora ainda não esclarecida, a germinação lenta de sementes de cafeeiro tem sido atribuída a diversas causas, como a presença do endocarpo (GUIMARÃES, 1995; RENA \& MAESTRI, 1986; VALIO, 1976), à baixa absorção de água e $\mathrm{O}_{2}$ (BENDAÑA, 1962), ao balanço hormonal (SILVA, 2002), ou à presença de substâncias inibidoras (FRIEDMAN \& WALLER, 1983; WALLER et al., 1986).

Alguns estudos têm sido desenvolvidos com sementes de cafeeiro, utilizando tratamentos prégerminativos na tentativa de aumentar o índice de velocidade de germinação, bem como o percentual de germinação das sementes. Camargo (1998) e Lima (1999), estudando o efeito do condicionamento osmótico sobre a qualidade fisiológica de sementes de cafeeiro, concluíram que os tratamentos que envolveram a embebição direta em água contribuíram para o envigoramento das sementes. Resultados semelhantes foram obtidos por Guimarães (2000), que concluiu que a imersão das sementes em água por 8 dias a $30^{\circ} \mathrm{C}$, aumenta a taxa e a velocidade de germinação. Lima (2001), estudando os efeitos do condicionamento fisiológico de sementes de cafeeiro armazenadas por 9 meses, sobre a formação de mudas, concluiu que a embebição das sementes em água aerada por 12 dias a $25^{\circ} \mathrm{C}$, permitiu a formação de mudas para o plantio em dezembro.

Guimarães (1995) concluiu que as sementes de cafeeiro devem ter o endocarpo removido para acelerar o processo germinativo, confirmando dados obtidos por Franco (1970), que observou que em meio asséptico, as sementes com pergaminho não germinam, enquanto outras, desprovidas de pergaminho germinam normalmente. Em 1962, Bendaña já havia observado que uma das causas da lenta germinação de sementes de cafeeiro é a barreira à entrada de água, exercida pelo pergaminho. Para Válio (1976), no caso de germinação no solo, o pergaminho é rapidamente decomposto pela flora microbiana e, em meio asséptico a presença do pergaminho contribui para retardar a germinação. Velasco \& Gutierrez, citados por Rena \& Maestri (1986) destacam que os efeitos da presença do pergaminho, na velocidade de germinação, seja impedindo a difusão de gases ou exercendo barreira mecânica ao crescimento do embrião, são secundários quando 
comparados à presença de substâncias inibidoras da germinação. Silva (2002), estudando os mecanismos e a regulação da germinação de sementes de cafeeiro demonstrou que, embora giberelina (GA) exógena iniba a germinação das sementes, a protrusão da radícula depende da síntese de novo de GA endógena e, é inibida por uma concentração supra-ótima deste hormônio.

Estanislau (2002), com objetivo de caracterizar as diferentes fases do desenvolvimento de sementes de cafeeiro em relação à germinabilidade e à tolerância à dessecação, concluiu que as sementes germinam e adquirem tolerância à desidratação aos 210 dias da antese quando os frutos apresentam-se no estádio verde-cana. Estudando os mecanismos de tolerância à dessecação em sementes de cafeeiro em diferentes estádios de maturação, Guimarães (2000) observou que as sementes apresentam redução de vigor e de viabilidade quando submetidas à secagem, independentemente do método de secagem e, que entre os estádios verde e verde-cana houve um sensível aumento no vigor das sementes.

Segundo Finch-Savage (1992), pesquisas tem mostrado que sementes de cafeeiro maduras podem não ter o máximo vigor, devido, provavelmente, à iniciação do processo de germinação no final da maturação antes de atingirem o estádio cereja. Carvalho \& Alvarenga (1979) testaram sementes de frutos em vários estádios de desenvolvimento, e observaram que as sementes germinam mesmo quando o fruto encontra-se na fase de "chumbinho", embora numa porcentagem de germinação baixa.

De uma maneira geral, os trabalhos visando a redução do tempo de germinação de sementes de cafeeiro são realizados em condições controladas de laboratório. Embora já existam alguns indicativos de que o processo de germinação possa ser abreviado, são raros os trabalhos realizados sob condições de viveiro de mudas. Com o objetivo de testar alternativas para a redução do tempo de obtenção de mudas, realizou-se o presente experimento, utilizando-se a semeadura de frutos e de sementes em vários estádios de desenvolvimento, para a formação de mudas de meio ano.

\section{MATERIAL E MÉTODOS}

O experimento foi realizado no viveiro do Setor de Cafeicultura/DAG da UFLA, no período de junho a dezembro de 2003. Foram utilizados frutos e sementes de Coffea arabica L. cv. Rubi, colhidos em campo experimental da Universidade. A semeadura foi realizada no mês de maio de 2002 constando dos seguintes tratamentos: 1) frutos no estádio verde; 2) frutos no estádio verde, dez dias após a colheita, mantidos em temperatura ambiente; 3) frutos no estádio verde-cana; 4) frutos no estádio verde-cana, dez dias após a colheita, mantidos em temperatura ambiente; 5) frutos no estádio cereja; 6) sementes de frutos-cereja despolpados em despolpador manual e desmucilados por fermentação natural em água a $30^{\circ} \mathrm{C}$ por 24 horas, lavadas e secadas até $15 \%$ de teor de água; 7) sementes de frutoscereja despolpados em despolpador manual e desmucilados por fermentação natural em água a $30^{\circ} \mathrm{C}$ por 24 horas, lavadas e secadas até $15 \%$ e sem pergaminho; 8) sementes de frutos cereja despolpados em despolpador manual e desmucilados por fermentação natural em água a $30^{\circ} \mathrm{C}$ por 24 horas, lavadas e secadas até $15 \%$ de teor de água e préembebidas em água por seis dias; e 9) sementes de frutos cereja despolpados em despolpador manual e desmucilados por fermentação natural em água a $30^{\circ} \mathrm{C}$ por 24 horas, lavadas e secadas até $15 \%$, sem pergaminho e préembebidas em água por seis dias.

Foram utilizados saquinhos de polietileno perfurado nas dimensões de 11 x $22 \mathrm{~cm}$, e substrato padrão (CFSMG, 1999) constituído de terra, esterco, superfosfato simples e cloreto de potássio. Após o expurgo do substrato com brometo de metila (GUIMARÃES \& MENDES, 1998) e a preparação dos saquinhos, procedeu-se a semeadura direta, semeando-se duas sementes ou um fruto por saquinho, os quais foram cobertos com dois centímetros de substrato.

Foram realizadas regas diárias, capinas e demais tratos culturais quando necessários. $\mathrm{O}$ desbaste foi feito quando as mudas encontravam-se no estádio "orelha de onça" (iniciando a emissão do primeiro par de folhas verdadeiras) nas parcelas onde havia mais de uma plântula emersa.

Cada parcela experimental continha 24 saquinhos dispostos em quatro fileiras de seis saquinhos, sendo que os oito saquinhos centrais constituíam a parcela experimental útil. $\mathrm{O}$ delineamento experimental foi blocos casualizados e para as comparações de médias utilizou-se o Teste de ScottKnott a 5\% de probabilidade, transformando-se os dados percentuais em [(arc sen X.100-1/2 $)+0,5]$. A análise dos dados foi realizada através do programa Sisvar.

As seguintes avaliações foram realizadas ao longo do experimento:

a) Teste de emergência - realizado quando se constatou a estabilização da emergência, ou seja, aos 140 dias da semeadura, computando-se as plântulas emersas acima da superfície do substrato, com os resultados expressos em porcentagem.

b) Índice de velocidade de emergência-calculado utilizando-se os dados de contagens diárias de plântulas emersas no teste de emergência, segundo a fórmula proposta por Edmond \& Drapala (1958): 


$$
I V E=\frac{\left(N_{1} x_{1}\right)+\left(N_{2} x_{2}\right)+\ldots+\left(N_{n} x G_{n}\right)}{G_{1}+G_{2}+\ldots+G_{n}}
$$

IVE = índice de velocidade de emergência (dias); $\mathrm{G}_{1}, \mathrm{G}_{2}, \ldots, \mathrm{G}_{\mathrm{n}}=$ número de plântulas normais computadas na primeira, segunda, ..., última contagem;

$\mathrm{N}_{1}, \mathrm{~N}_{2}, \ldots, \mathrm{Nn}=$ número de dias da semeadura à primeira, segunda, ..., última contagem.

c) Porcentagem de plântulas com pelo menos um par de folhas verdadeiras - aos 140 dias foram computadas as plântulas com pelo menos um par de folhas verdadeiras o os resultados expressos em porcentagem.

d) Avaliação das mudas - após 180 dias do início do experimento, foram realizadas as seguintes medições, nas oito mudas úteis de cada parcela experimental:

d.1) Diâmetro de caule - obtido, por meio de um paquímetro, medindo-se os diâmetros das mudas, no ponto imediatamente abaixo da inserção das folhas cotiledonares, e calculando-se os diâmetros médios, com os resultados expressos em mm por planta;

d.2) Altura das mudas - obtida medindo-se a região compreendida entre o colo e o ponto de inserção dos brotos terminais das mudas, do ramo ortotrópico, calculando-se a média por muda, com os resultados expressos em $\mathrm{cm}$ por planta;

d.3) Área foliar - foram efetuadas medições do comprimento e da largura de uma de cada par de folhas verdadeiras; a área foliar de cada par de folhas foi obtida pelo produto largura x comprimento x 0,667 x 2 (par de folhas), proposta por Barros et al. (1973); a área foliar da muda foi obtida pelo somatório das áreas dos pares de folhas de cada planta; a área foliar média foi obtida a partir dos valores das áreas foliares das mudas da parcela, com os resultados expressos em $\mathrm{cm}^{2}$.

d.4) Massa seca do sistema radicular e da parte aérea - as mudas foram retiradas dos saquinhos, lavadas em água corrente e em seguida o sistema radicular foi separado da parte aérea, cortando-se o caule na altura do colo; foram obtidos os pesos do sistema radicular e da parte aérea das plantas úteis da parcela, após secagem em estufa de circulação forçada de ar a $60^{\circ} \mathrm{C}$, até peso constante, com os resultados médios expressos em gramas/ planta;

d.5) Número de pares de folhas verdadeiras - foram computados os números de pares de folhas das plantas úteis da parcela e calculado o número médio de folhas verdadeiras por planta.

\section{RESULTADOS E DISCUSSÃO}

As diferenças entre os tratamentos de semeadura foram significativas, ao nível de $1 \%$ para quase todas as características de avaliação do desenvolvimento e formação das mudas, exceto para as razões massa seca de parte aérea/massa de sistema radícular (MSPA/MSSR) e MSSR/MSPA (Tabela 1).

TABELA 1 - Resultados médios das avaliações das plântulas de Coffea arabica L. cv. Rubi, oriundas da semeadura de sementes ou frutos em diversos estádios de desenvolvimento. Embrapa Café/UFLA, Lavras - MG, 2003.

\begin{tabular}{lccc}
\hline \multicolumn{1}{c}{$\begin{array}{c}\text { Tratamentos } \\
\text { Tipos de semeadura }\end{array}$} & $\begin{array}{c}\text { Emergência } \\
(\boldsymbol{\%})\end{array}$ & $\begin{array}{c}\text { Índice de velocidade de } \\
\text { emergência }\end{array}$ & $\begin{array}{c}\text { Mudas com pelo menos 1 } \\
\text { par de folhas (\%) }\end{array}$ \\
\hline 1. Fruto verde & $58 \mathrm{~B}$ & $114,95 \mathrm{C}$ & $0 \mathrm{C}$ \\
2. Fruto verde 10 dias após a colheita & $62 \mathrm{~B}$ & $107,60 \mathrm{C}$ & $1 \mathrm{C}$ \\
3. Fruto verde-cana & $87 \mathrm{~A}$ & $87,95 \mathrm{~B}$ & $32 \mathrm{~B}$ \\
4. Fruto verde-cana 10 dias após a colheita & $87 \mathrm{~A}$ & $96,08 \mathrm{~B}$ & $3 \mathrm{C}$ \\
5. Fruto cereja & $92 \mathrm{~A}$ & $86,94 \mathrm{~B}$ & $31 \mathrm{~B}$ \\
6. Semente com pergaminho & $94 \mathrm{~A}$ & $81,30 \mathrm{~B}$ & $73 \mathrm{~A}$ \\
7. Semente sem pergaminho & $94 \mathrm{~A}$ & $56,62 \mathrm{~A}$ & $91 \mathrm{~A}$ \\
8. Sementes com pergaminho + primming & $93 \mathrm{~A}$ & $85,27 \mathrm{~B}$ & $35 \mathrm{~B}$ \\
9 Sementes sem pergaminho + primming & $86 \mathrm{~A}$ & $59,31 \mathrm{~A}$ & $74 \mathrm{~A}$ \\
\hline
\end{tabular}

Médias seguidas da mesma letra nas colunas diferem entre si pelo teste de Scott-Knott, ao nível de 5\% de probabilidade.

Ciênc. agrotec., Lavras, v. 31, n. 2, p. 349-356, mar./abr., 2007 
Observa-se pelos dados de porcentagem de emergência, que as plântulas originadas de frutos verdes foram estatisticamente inferiores e os demais tratamentos não apresentaram diferenças significativas para esta avaliação. Estes tratamentos diferenciaram-se apenas pela velocidade com que as sementes emergiram do solo. Quanto menor o valor do índice de velocidade de emergência das sementes, proposto por Edmond \& Drapala (1958), melhor é o desempenho fisiológico das sementes, pois o índice representa o número de dias gastos para a obtenção do máximo percentual de emergência. Nesta característica de vigor de plântulas, pode-se observar que as mudas que mais se destacaram foram aquelas originadas da semeadura de sementes sem pergaminho (Tabela 1).

Maiores velocidades de emergência também foram observadas por outros pesquisadores, quando se usam sementes sem pergaminho (GUIMARÃES, 1995; RENA \& MAESTRI, 1986; VÁLIO, 1976). Guimarães (1995), em suas pesquisas sobre o efeito do pergaminho na germinação de sementes de cafeeiro, concluiu que para acelerar o processo germinativo, as sementes devem ter o pergaminho retirado de maneira que o embrião não seja danificado.

O melhor desempenho fisiológico das sementes sem pergaminho foi constatado em todas as avaliações de desenvolvimento das mudas. Observa-se que mesmo nas características em que este tratamento não diferiu estatisticamente dos demais tratamentos, as mudas originadas de sementes sem pergaminho, foram as que resultaram em mudas com maior crescimento. Deve ser destacado que a embebição das sementes com pergaminho em água não ofereceu nenhuma vantagem à formação das mudas, uma vez que este tratamento proporcionou valores estatisticamente inferiores para todas as características (Tabela 2). Na Figura 1, pode ser observado o aspecto das plântulas correspondentes aos tratamentos de semeadura, aos 140 dias de desenvolvimento, quando se destacaram as plântulas originadas de sementes sem pergaminho.

Sendo o cafeeiro uma planta perene, é de fundamental importância o emprego de mudas vigorosas para a implantação da lavoura e, no presente estudo, ficou evidente a superioridade das mudas originadas de sementes sem pergaminho, com valores de massa seca do sistema radicular, da parte aérea e da área foliar, superiores aos demais tratamentos, inclusive do semeio tradicional de sementes com pergaminho. Tal fato revela o maior vigor destas mudas e demonstra a necessidade e o interesse na busca de soluções práticas para a remoção (química ou mecânica) do pergaminho das sementes, antes ou durante a semeadura.

TABELA 2 - Resultados médios das avaliações das mudas de Coffea arabica L. cv. Rubi, oriundas da semeadura de sementes e frutos em diversos estádios de desenvolvimento. Embrapa Café/UFLA, Lavras - MG, 2003.

\begin{tabular}{|c|c|c|c|c|c|c|c|c|}
\hline $\begin{array}{c}\text { Tratamentos } \\
\text { Tipos de semeadura }\end{array}$ & $\begin{array}{c}\text { Diâmetro } \\
\text { de caule } \\
(\mathrm{mm})\end{array}$ & $\begin{array}{c}\text { Altura } \\
\text { de } \\
\text { planta } \\
(\mathrm{cm})\end{array}$ & $\begin{array}{c}\text { Massa } \\
\text { seca da } \\
\text { parte } \\
\text { aérea } \\
\text { MSPA } \\
\text { (g) }\end{array}$ & $\begin{array}{c}\text { Massa } \\
\text { seca do } \\
\text { sistema } \\
\text { radic. } \\
\text { MSSR } \\
\text { (g) }\end{array}$ & $\begin{array}{l}\text { MSSR/ } \\
\text { MSPA }\end{array}$ & $\begin{array}{l}\text { MSPA/ } \\
\text { MSSR }\end{array}$ & $\begin{array}{c}\text { Área } \\
\text { Foliar } \\
\left(\mathrm{cm}^{2}\right)\end{array}$ & $\begin{array}{l}\text { Número de } \\
\text { pares de } \\
\text { folhas } \\
\text { verdadeiras }\end{array}$ \\
\hline 1. Fruto verde & $2,95 \mathrm{~A}$ & $11,60 \mathrm{D}$ & $6,46 \mathrm{~B}$ & $1,50 \mathrm{~B}$ & $0,233 \mathrm{~B}$ & $4,445 \mathrm{~A}$ & $159,39 \mathrm{~B}$ & $3,89 \mathrm{C}$ \\
\hline 2. Fruto verde 10 dias após a colheita & $2,69 \mathrm{~B}$ & $11,98 \mathrm{D}$ & $6,56 \mathrm{~B}$ & $1,38 \mathrm{~B}$ & $0,208 \mathrm{~B}$ & $4,778 \mathrm{~A}$ & $156,81 \mathrm{~B}$ & $3,94 \mathrm{C}$ \\
\hline 3. Fruto verde-cana & $2,97 \mathrm{~A}$ & $15,14 \mathrm{~A}$ & $9,52 \mathrm{~A}$ & $2,30 \mathrm{~A}$ & $0,240 \mathrm{~A}$ & $4,260 \mathrm{~A}$ & $222,07 \mathrm{~A}$ & $4,91 \mathrm{~A}$ \\
\hline 4. Fruto verde-cana 10 dias após a colheita & $2,70 \mathrm{~B}$ & $12,72 \mathrm{D}$ & $6,96 \mathrm{~B}$ & $1,72 \mathrm{~B}$ & $0,248 \mathrm{~A}$ & $4,133 \mathrm{~A}$ & $173,90 \mathrm{~B}$ & $4,41 \mathrm{~B}$ \\
\hline 5. Fruto cereja & $3,03 \mathrm{~A}$ & $14,92 \mathrm{~B}$ & $9,81 \mathrm{~A}$ & $2,34 \mathrm{~A}$ & $0,243 \mathrm{~A}$ & $4,208 \mathrm{~A}$ & $231,23 \mathrm{~A}$ & $4,91 \mathrm{~A}$ \\
\hline 6. Semente com pergaminho & $3,01 \mathrm{~A}$ & $15,91 \mathrm{~B}$ & $9,90 \mathrm{~A}$ & $1,94 \mathrm{~B}$ & $0,195 \mathrm{~B}$ & $5,178 \mathrm{~A}$ & $233,30 \mathrm{~A}$ & $5,13 \mathrm{~A}$ \\
\hline 7. Semente sem pergaminho & $3,11 \mathrm{~A}$ & $17,05 \mathrm{~A}$ & $11,57 \mathrm{~A}$ & $2,96 \mathrm{~A}$ & $0,253 \mathrm{~A}$ & $4,003 \mathrm{~A}$ & $241,26 \mathrm{~A}$ & $5,31 \mathrm{~A}$ \\
\hline 8. Sementes com pergaminho + primming & $2,82 \mathrm{~B}$ & $13,98 \mathrm{C}$ & $8,19 \mathrm{~B}$ & $1,68 \mathrm{~B}$ & $0,203 \mathrm{~B}$ & $5,098 \mathrm{~A}$ & $192,34 \mathrm{~B}$ & $4,56 \mathrm{~B}$ \\
\hline 9 Sementes sem pergaminho + primming & $3,02 \mathrm{~A}$ & $16,82 \mathrm{~A}$ & $11,10 \mathrm{~A}$ & $2,44 \mathrm{~A}$ & $0,218 \mathrm{~A}$ & $4,603 \mathrm{~A}$ & $192,27 \mathrm{~B}$ & $5,41 \mathrm{~A}$ \\
\hline
\end{tabular}

Médias seguidas da mesma letra nas colunas diferem entre si pelo teste de Scott Knott, ao nível de $5 \%$ de probabilidade. 
Outro fato observado no presente estudo foi o desempenho das mudas originadas de frutos no estádio verde-cana, as quais se equipararam estatisticamente ao melhor tratamento (sementes sem pergaminho), em quase todas as avaliações (Tabela 2). Somente o índice de velocidade de emergência e porcentagem de mudas com pelo menos um par de folhas verdadeiras aos 140 dias foram menores para este tratamento. Observa-se que as mudas originadas de frutos verde-cana apresentaram desempenho igual ou superior àquelas originadas de sementes com pergaminho, ou seja, desempenho similar às mudas produzidas de acordo com o procedimento técnico recomendado para a formação de mudas comerciais. Sementes de Coffea arabica L. apresentam máxima germinação no estádio verde-cana (ESTANISLAU, 2002; GUIMARÃES, 2000) e, segundo Finch-Savage (1992), podem apresentar também, maior vigor, porque no estádio cereja as sementes podem já ter iniciado o processo de germinação, uma vez que não entram em quiescência metabólica e, portanto, podem apresentar maior sensibilidade às condições de estresse. Sementes mais vigorosas são altamente desejáveis, principalmente considerando-se as condições de baixa temperatura a que as mudas estão sujeitas durante o período de formação, na maioria das regiões de produção de mudas de cafeeiro.

Os dados obtidos no presente estudo indicam a possibilidade de obtenção de mudas com padrão de qualidade aceitável para o plantio, a partir da semeadura de um fruto no estádio verde-cana, ao invés de duas sementes oriundas de fruto no estádio cereja. Entretanto, a recomendação da semeadura de um fruto verde-cana por saquinho deve ser mais bem estudada, pois se trata de um trabalho conduzido com apenas uma cultivar de Coffea arabica L., não podendo, portanto, serem os resultados generalizados para outros cultivares.

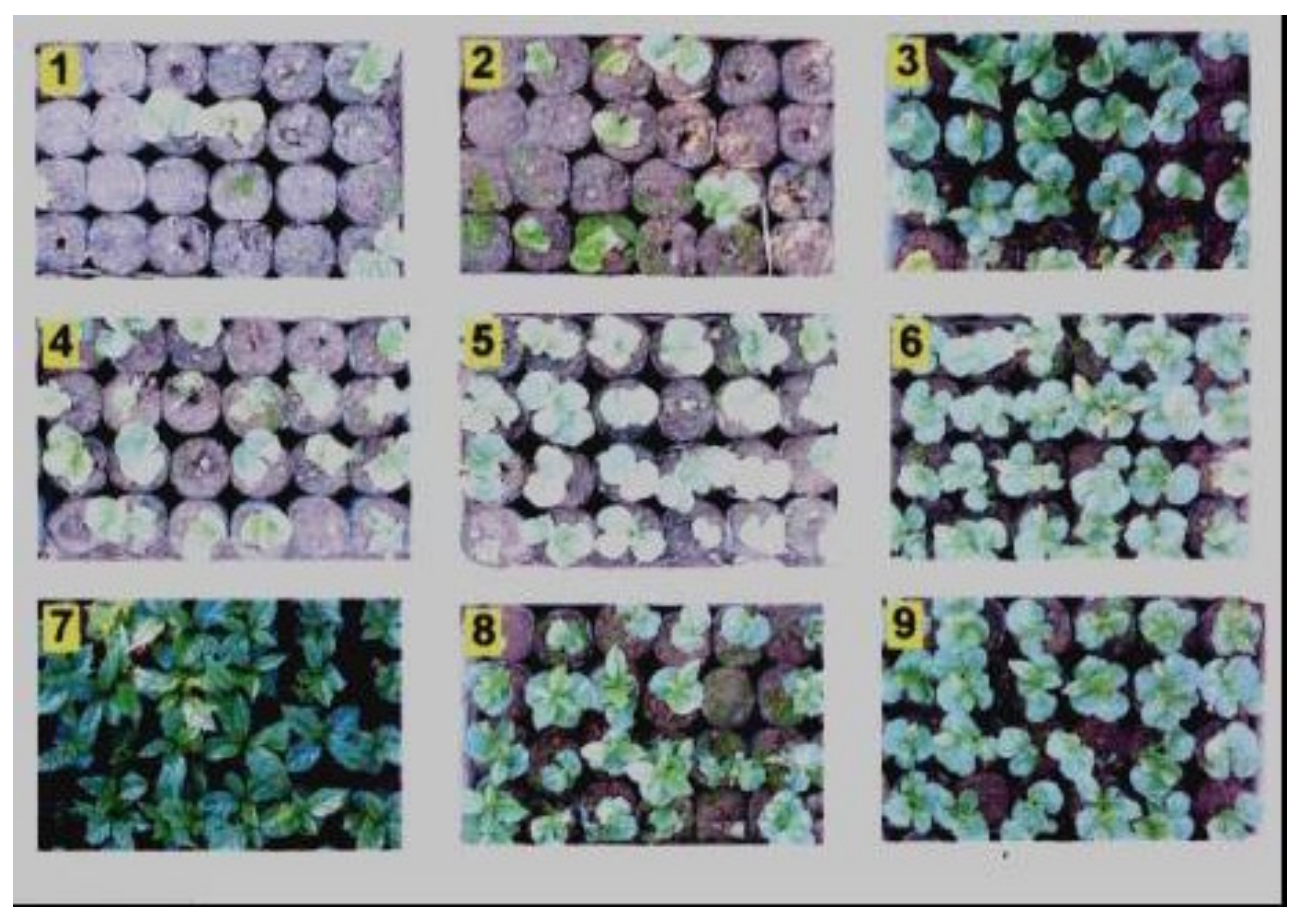

FIGURA 1 - Aspectos das plântulas de Coffea arabica L. cv. Rubi, originadas da semeadura (1) do fruto no estádio verde; (2) do fruto no estádio verde dez dias após colheita; (3) do fruto no estádio verde-cana; (4) do fruto no estádio verde-cana dez dias após a colheita; (5) do fruto no estádio cereja; (6) da semente de fruto cereja, desmucilada e secada até $15 \%$ de teor de água; (7) da semente de fruto cereja, desmucilada, secada até 15\% e sem pergaminho; (8) da semente de fruto cereja, desmucilada, secada até $15 \%$ de teor de água e pré-embebida em água por seis dias; e (9) da semente de fruto cereja, desmucilada, secada até 15\%, sem pergaminho e pré-embebida em água por seis dias. Embrapa Café/UFLA, Lavras - MG, 2003. 
Com referência aos valores das razões MSSR/ MSPA, pode-se observar que os tratamentos que se destacaram nesta avaliação foram também os que se destacaram nas demais características avaliadas (Tabela 2). No entanto, as razões MSPA/MSSR não apresentaram diferenças significativas entre os tratamentos de semeadura estudados, situando-se esta relação entre quatro e cinco. Kainuma et al. (2001), citados por Vallone (2003), enfatizaram que razões MSPA/MSSR entre quatro e sete são consideradas ideais para mudas apresentando uma média de cinco pares de folhas e, que uma relação entre parte aérea/sistema radicular menor é interessante, podendo favorecer o "pegamento" das mudas no campo. Vallone (2003), estudando os efeitos de polímeros hidro-retentores, diferentes substratos e adubações na produção de mudas de cafeeiro em tubetes, também não encontrou diferenças significativas entre as razões MSPA/MSSR. O autor comenta que para a determinação da razão MSPA/MSSR ideal, são necessárias avaliações do desenvolvimento de mudas com diferentes relações entre parte aérea e sistema radicular no campo.

As mudas de meio ano gastam em média, seis meses para serem formadas e podem ser levadas para o campo quando apresentarem de três a quatro pares de folhas verdadeiras. Observou-se, neste trabalho, que na época em que as mudas foram avaliadas, ou seja, aos 180 dias da semeadura, todos os tratamentos apresentaram média superior a 3,9 pares de folhas. Os tratamentos que se destacaram, apresentaram uma média de até 5,4 pares de folhas, porém não foram determinados os tempos para que as mudas, em cada tratamento de semeadura, atingissem o ponto comercial, ou seja, o número de dias, contados a partir da semeadura, quando $80 \%$ das mudas úteis da parcela atingissem três pares de folhas verdadeiras e início da emissão do quarto par. Certamente, este dado indicaria o tratamento mais vantajoso, do ponto de vista da redução do período de formação da muda, permitindo o plantio das mudas durante o período chuvoso e não no final deste, como normalmente ocorre.

\section{CONCLUSÕES}

Os tratamentos de semeadura de sementes sem pergaminho se destacaram em todas as características avaliadas e apresentaram praticamente o mesmo desempenho das mudas de sementes sem pergaminho e pré-embebidas em água por seis dias.

Nas características de avaliação das mudas, os tratamentos de semeadura de frutos no estádio verde-cana e de sementes sem pergaminho não diferiram estatisticamente entre si e foram superiores à semeadura de sementes com pergaminho.

A embebição de sementes de cafeeiro com pergaminho em água, não oferece vantagens na formação de mudas.

\section{REFERÊNCIAS BIBLIOGRÁFICAS}

ANUÁRIO estatístico do café. Rio de Janeiro: Coffee Business, 2002/2003. 101 p.

BARROS, R. S.; MAESTRI, M.; BRAGA FILHO, L. J. Determinação da área de folhas de café (Coffea arabica L., cv. Bourbon amarelo). Revista Ceres, Viçosa, v. 20, n. 107, p. 44-53, jan./mar. 1973.

BENDAÑA, F. E. Fisiologia de las semillas de café: problemas relativos al almacinamento, café. Turrialba, Turrialba, v. 4, n. 15, p. 99-106, 1962.

CAMARGO, R. Condicionamento fisiológico de sementes de cafeeiro(Coffea arabica L.). 1998. 108 p. Dissertação (Mestrado em Fitotecnia) - Universidade Federal de Lavras, Lavras, 1998.

CARVALHO, G. R. Germinação de sementes e aclimatização de plântulas de cafeeiro (Coffea arabica $\mathrm{L}$.) propagadas “in vitro". 1997. 64 f. Dissertação (Mestrado em Fitotecnia) - Universidade Federal de Lavras, Lavras, 1997.

CARVALHO, M. M. de; ALVARENGA, G. Determinação do estádbbio de desenvolvimento mínimo do fruto do cafeeiro (Coffea arabica L.), para a germinação. In: CONGRESSO BRASILEIRO DE PESQUISAS CAFEEIRAS, 7., 1979, Araxá. Resumos... Rio de Janeiro: IBC-GERCA, 1979. p. 118-119.

COMISSÃO DE FERTILIDADE DO SOLO DO ESTADO DE MINAS GERAIS. Recomendações para o uso de corretivos e fertilizantes em Minas Gerais: $5^{\text {a }}$ aproximação. Lavras, 1999. 359 p.

EDMOND, J. B.; DRAPALA, W. S. The effects of temperature, sand and acerone on germination of okra seed. Proceedings of American Society for Horticultural Science, New York, v. 71, p. 428-434, June, 1958.

ESTANISLAU, W. T. Modelo funcional de desenvolvimento de sementes de cafeeiro (Coffea arabica L.). 2002. 125 p. Dissertação (Mestrado em Fitotecnia) - Universidade Federal de Lavras, Lavras, 2002. 
FINCH-SAVAGE, W. E. Seed development in the recalcitrant species Quercus robur L.: germinability and desiccation tolerance. Seed Science Research, [S.1.], v. 2, p. 17-22, 1992 .

FRANCO, C. M. Apontamentos de fisiologia do cafeeiro. Campinas: Secretaria da Agricultura do Estado de São Paulo, 1970. $55 \mathrm{p}$.

FRIEDMAN, J.; WALLER, G. R. Caffeine hazards and their prevention in germinating seeds of coffee (Coffea arabica L.). Seed Science Research, [S.1.], v. 9, p. 1099-1106, 1983.

GUIMARÃES, R. J.Formação de mudas de cafeeiro: (Coffea arabida $\mathrm{L}$.): efeitos de reguladores de crescimento $\mathrm{e}$ remoção do pergaminho na germinação de sementes e do uso de $\mathrm{N}$ e $\mathrm{K}$ em cobertura, no desenvolvimento de mudas. 1995. 133 f. Tese (Doutorado em Fitotecnia) - Universidade Federal de Lavras, Lavras, 1995.

GUimarÃES, R. M. Tolerância à dessecação e condicionamento fisiológico em sementes de cafeeiro (Coffea arabica L.). 2000. 180 p. Tese (Doutorado em Fitotecnia) - Universidade Federal de Lavras, Lavras, 2000.

GUIMARÃES, R. J.; MENDES, A. N. G. Produção de mudas de cafeeiro. In: MENDES, A. N. G.; GUIMARÃES, R. G. (Eds.). Cafeicultura empresarial: produtividade e qualidade. Lavras: UFLA/FAEPE, 1998. p. 1-60.

LIMA, S. M. P. Condicionamento fisiológico de sementes de cafeeiro: efeitos na germinação, vigor e formação de mudas. 2001. 161 p. Dissertação (Mestrado em Fitotecnia) - Universidade Federal de Lavras, Lavras, 2001.

LIMA, W. A. A. Condicionamento fisiológico, germinação e vigor de sementes de café (Coffea arabica L.). 1999. $69 \mathrm{f}$. Dissertação (Mestrado em Fitotecnia) - Universidade Federal de Viçosa, Viçosa, 1999.

RENA, A. B.; MAESTRI, M. Fisiologia do Cafeeiro. In: SIMPÓSIO SOBRE FATORES QUE AFETAM A PRODUTIVIDADE DO CAFEEIRO, 1986, Poços de Caldas. Anais... Piracicaba: POTAFÓS, 1986. p. 13-85.

SILVA, E. A. A. da. Coffee (Coffee arabica L., cv. Rubi) seed germination: mechanism and regulation. 2002. 105 $\mathrm{f}$. Thesis $(\mathrm{PhD})$ - Wageningen University, Wageningen, 2002.

VALIO, I. F. M. Germination of coffee seeds (Coffea arabica L.), cv. Mundo Novo. Journal of Experimental Botany, Oxford, v. 27, n. 100, p. 983-991, Oct. 1976.

VALLONE, H. S. Produção de mudas de cafeeiro (Coffea arabica L.) em tubetes com polímero hidroretentor, diferentes substratos e adubações. 2003.75 p. Dissertação (Mestrado em Fitotecnia) - Universidade Federal de Lavras, Lavras, 2003.

WALLER, G. R.; KUMARI, D.; FRIEDMAN, J.; FRIEDMAN, N.; CHOU, C. H. Caffeine Autotoxicity in Coffea arabica L. In: The science of allelopathy. New York: J. Wiley and Sons, 1986. p. 243-263. 